\title{
Stress-Induced Phase Transformation and Room Temperature Aging in Ti-Nb-Fe Alloys S. Cai ${ }^{1}$, J.E. Schaffer ${ }^{1}$, Y. Ren ${ }^{2}$
}

${ }^{1}$ Fort Wayne Metals Research Products Corp, 9609 Ardmore Ave., Fort Wayne, IN 46809 USA

${ }^{2}$ Advanced Photon Source, Argonne National Laboratory, 9700 S. Cass Ave., Argonne, IL 60439 USA

\begin{abstract}
:
Room temperature deformation behavior of $\mathrm{Ti}-17 \mathrm{Nb}-1 \mathrm{Fe}$ and $\mathrm{Ti}-17 \mathrm{Nb}-2 \mathrm{Fe}$ alloys was studied by synchrotron X-ray diffraction and tensile testing. It is found that, after proper heat treatment, both alloys were able to recover a deformation strain of above $3.5 \%$ due to the Stress-induced Martensite (SIM) phase transformation. Higher Fe content increased the beta phase stability and onset stress for SIMT. For the same reason, a strong $\{110\}_{\beta}$ texture was produced in Ti-17Nb$2 \mathrm{Fe}$ compared to the $\{210\}_{\beta}$ texture that was observed in Ti-17Nb-1Fe. Room temperature aging was observed in both alloys, where the formation of the omega phase increased the yield strength (also SIM onset stress), and decreased the ductility and strain recovery. The phenomenon might be a common feature of most metastable beta $\mathrm{Ti}$ alloys and should draw more attention to scientist and engineers in material designs and selections.
\end{abstract}

\section{Introduction}

The shape memory and super-elastic constitutive responses of nitinol (NiTi) have underpinned advanced medical applications since revolutionizing the stent industry with self-expanding devices beginning in the 1990's [1-2]. Since 2000, the high strain recovery of nitinol alloys has 
enabled life-changing technologies including neural guidewires, cerebral aneurysm occluders, and over-the-wire heart valve frames. However, the high $\mathrm{Ni}$ content in NiTi alloys comprises a perceived, sometimes realized threat to patients who are allergic to $\mathrm{Ni}$ [3-4]. Considering that about $16 \%$ of the population is allergic to $\mathrm{Ni}$ [5], demand for Ni-free materials with super-elastic properties is high. Past efforts have primarily focused on $\beta$-Ti alloys due to relatively large strain recovery caused by the Stress-Induced Martensite (SIM) transformation as well as their corrosion resistance and relative biocompatibility. During SIM transformation, the austenitic $\beta$-phase (with a $b c c$ crystal structure) transforms to martensitic $\alpha$ "-phase (with an orthorhombic structure). This transformation and the strain associated with the structural change are reversible if the $\beta$-phase is stable at room temperature and the alloy is sufficiently strong to thwart significant plasticity during stress-driven transformation, and can drive large strain recovery upon unloading. The total strain recovery of a material depends on microstructural features such as phase fractions, dislocation structures and textures, which are controlled by processing history [6-7]. The maximum theoretical recoverable strain is determined by lattice parameters of the $\beta$ parent and $\alpha$ "-daughter phases. For $\beta$-Ti alloys, the maximum transformation strain is caused by the $\langle 110\rangle_{\beta} \rightarrow\langle 020\rangle_{\alpha}$, transition, which is controlled by the chemical composition [6]. Kim et al.'s studies on the Ti-Nb system [6] show that the transformation strain increases with decreasing $\mathrm{Nb}$ content, and a strain of above $6 \%$ can be obtained when the $\mathrm{Nb}$ is less than 17 at.\%. This strain level is significantly higher than that (e.g. 3-4\%) routinely reported in most of the other $\beta$-Ti alloys $[6,7,8,9]$. However, the decreased $\mathrm{Nb}$ also increases the martensite transformation to above body temperature thus precluding SIM transformation during body temperature deformation. This has been confirmed by our work on a Ti-17 at.\% $\mathrm{Nb}$ alloy, which contains a large amount of $\alpha "$ and $\omega$-phases at room temperature after annealing [10]. To 
stabilize the $\beta$-matrix and decrease the martensitic transformation temperature, a very strong $\beta$ stabilizer, Fe, was added. Previous work [11] suggests that $\mathrm{Fe}$ is $\sim 10$ times more effective than $\mathrm{Nb}$ in stabilizing the $\beta$-phase. 1 at $\%$ Fe could drop the martensite-start $(M s)$ temperature by 240 $\mathrm{K}$ [12]. Therefore, 1 to 2 at.\% Fe, was added to the system. The deformation behavior, phase transformation and textures were characterized by in-situ synchrotron X-ray diffraction. The total strain recovery was tested by loading and unloading in a uniaxial tensile test. Synchrotron X-ray and tensile testing were also used to evaluate the materials' room temperature aging behavior. Study of this Ti-Nb-Fe alloy system provides useful insight into the process-structure-function design of Ni-free medical technology, and in design and application with stabilized $\beta$-Ti alloys in general.

\section{Materials and experiments}

Two beta Ti alloys with chemical compositions of Ti-17Nb-1Fe and Ti-15Nb-2Fe (at.\%) were Arc-melted three times in vacuum and then drop-casted into two $\emptyset 19 \times 140 \mathrm{~mm}$ ingots. These two alloys are called " $1 \mathrm{Fe}$ " and " $2 \mathrm{Fe}$ " hereafter. After homogenization annealing at $1000^{\circ} \mathrm{C}$ for 72 hours in a quartz tube, these ingots were extruded at 950 to $1000^{\circ} \mathrm{C}$ to rods with a diameter of 8 $\mathrm{mm}$ and then cold drawn to a diameter of $0.45 \mathrm{~mm}$ by traditional wire drawing and annealing processes. The amount of cold work after the last process anneal was $90 \%$ (2.3 true strain) and 98\% (4.2 true strain) for $1 \mathrm{Fe}$ and $2 \mathrm{Fe}$ respectively. To understand the deformation mechanisms of these two alloys, in-situ synchrotron X-ray diffraction tensile testing was carried out on beam line 11-ID-C at the Advanced Photon Source (APS) at Argonne National Laboratory. Samples were heat treated at $750^{\circ} \mathrm{C}$ for $6 \mathrm{~s}$ in argon, and cooled to room temperature within 15 seconds by pressurized gas. Experiments of these two alloys were performed at different times with different 
$\mathrm{X}$-ray wavelengths. For $1 \mathrm{Fe}$, the wavelength was $0.11165 \AA$, while for $2 \mathrm{Fe}$ alloy, the wavelength was $0.11798 \AA$. The experimental setups were similar to those used previously $[13,14]$. The specimen gauge length was $20 \mathrm{~mm}$. Tests were performed under displacement control at a deformation rate of $0.5 \times 10^{-3} \mathrm{~s}^{-1}$. At selected points, the specimen was held at constant strain for $10 \mathrm{~s}$ for data collection, where the 2-D diffraction images were recorded by a Perkin-Elmer 143 detector. During the test, the specimen was continuously loaded to an engineering strain of $\sim 3.5 \%$, where clear phase transformation was observed. The "raw" data were processed in FIT2D software [15]. Phase fractions and textures were estimated by Rietveld refinement [16] embedded in the MAUD software [17]. Lattice strains were analyzed by using GSAS software [18]. More details can be found in previous work [13].

To understand the influence of heat treating parameters on material properties, cold drawn wires were annealed at temperatures from 600 to $800^{\circ} \mathrm{C}$ for various dwells, and immediately tested on an Instron 5966 tensile tester. The sample gauge length was $127 \mathrm{~mm}$. Test was under displacement control at a deformation rate of $1.6 \times 10^{-3} \mathrm{~s}^{-1}$. During the test, the sample was continuously loaded to a strain of $4 \%$ and unloaded to zero stress. Test results were used to evaluate the strain recovery capability of both alloys across the varied thermal recipes.

During the study, it was noticed that both materials experienced a certain degree of room temperature aging, which changed their mechanical properties. To investigate this behavior, new samples were made from these two alloys with similar dimensions and cold work levels. Samples were tensile tested at different times after heat treatment ranging from "fresh" to several days of storage. Synchrotron X-ray diffraction was also performed on heat treated samples after aging at room temperature for different amount of time to monitor the changes on the microscopic scale. 


\section{Results and discussions}

\subsection{SIM phase transformation}

Figure 1 shows the stress-strain curves of $1 \mathrm{Fe}$ and $2 \mathrm{Fe}$, respectively, during the in-situ tensile test. For $1 \mathrm{Fe}$, double yield was observed at stresses of approximately 500 and $770 \mathrm{MPa}$. It is generally assumed that the first "yield" at $500 \mathrm{MPa}$ indicates the onset of SIM transformation, while the second yield at the stress of $770 \mathrm{MPa}$ is caused by dislocation slip [19,20 ]. The evidence of SIM phase transformation in 1Fe is shown in Fig.1c, where diffractions of the $(020)_{\alpha "}$ and $(021)_{\alpha "}$ martensite families can be seen at a strain of $\sim 3 \%$. Although double yielding behavior was not seen in 2Fe, SIM was still observed at the 3\% strain (Fig.1f). The $\omega$-phase was also observed in both alloys before deformation (Figs.1b and e). Compared to that in 1Fe, a much stronger $\{110\}_{\beta}$ diffraction is seen in $2 \mathrm{Fe}$ along the sample's axial direction (Figs.1b and e). In addition, the diffraction patterns of the $\{200\}_{\beta}$ in these two alloys are slightly different. These differences reflect the different $\beta$-phase textures, which are shown in Figures 2 and 3. Before deformation, the $\beta$-phase in 1 Fe had a strong $\{210\}_{\beta}$ texture and a weak $\{110\}_{\beta}$ texture in the axial direction, while the $\omega$-phase, at approximately 21 mass $\%$, had a strong $\{22 \overline{4} 3\}_{\omega}$ texture and a relatively weaker $\{11 \overline{2} 0\}_{\omega}$ texture. Texture patterns of both phases were static throughout

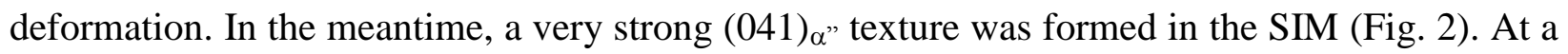
strain of 3\%, about 20 mass $\%$ SIM phase was formed, while the fraction of the $\omega$-phase declined to 17.5 mass $\%$. On the other hand, $2 \mathrm{Fe}$ had very strong $\{110\}_{\beta}$ and $\{11 \overline{2} 0\}_{\omega}$ textures before and after deformation. Similar to that in $1 \mathrm{Fe}$, the $\omega$-phase fraction in $2 \mathrm{Fe}$ was slightly decreased from 18.5 mass $\%$ to 17 mass $\%$ after deformation. About 35 mass\% SIM was formed at a strain of 3\%, and the SIM showed a strong $(010)_{\alpha}$ " texture, which is $\sim 14^{\circ}$ away from the $(041)_{\alpha}$ " texture 
formed in $1 \mathrm{Fe}$. Lattice parameters of different phases in each alloy are listed in Table 1. Based on these numbers, the maximum transformation strain, from $[110]_{\beta} \rightarrow[010]_{\alpha "}$, is $\sim 4 \%$ in $1 \mathrm{Fe}$, and $\sim 2.5 \%$ in $2 \mathrm{Fe}$.

A previous study [21] proposed that the $\{210\}_{\beta}$ texture is caused by $\{112\}_{\beta}$ and $\{332\}_{\beta}$ twinning, and only present in $\beta$-Ti alloys with low $\beta$-phase stability. Those with high $\beta$-phase stability, such as $\beta-\mathrm{C}$ Ti alloy, will have the typical $\{110\}_{\beta}$ texture after the drawing process. Therefore, different textures between $1 \mathrm{Fe}$ and $2 \mathrm{Fe}$ are related to different $\beta$-phase stabilities due to their different amount of Fe content. Nevertheless, textures of different phases in both alloys follow their crystal orientation relationship. According to the orientation relationship between the $\beta-, \omega$ - and $\alpha$ "-phases [21], the following lattice correspondence exists, viz.: $[1 \overline{1} 0]_{\beta} \rightarrow[11 \overline{2} 0]_{\omega}$ and $[011]_{\beta} \rightarrow[010]_{\alpha}$. Therefore, a $\{110\}_{\beta}$ texture will produce a $\{11 \overline{2} 0\}_{\omega}$ texture in $\omega$-phase and

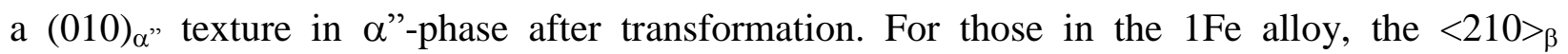
direction is parallel to the $[112]_{\omega}$ (i.e. $[11 \overline{2} 6]_{\omega}$ ) direction based on the calculation [10], which is very close to the $(22 \overline{4} 3)_{\omega}$ plane normal (i.e. $\left[\begin{array}{lll}1.8 & 1.8 & 3.7\end{array}\right]_{\omega}$ direction). Therefore, a strong $\{210\}_{\beta}$ texture could result in a strong $\{22 \overline{4} 3\}_{\omega}$ texture after phase transformation. Similarly, the $\langle 210\rangle_{\beta}$ direction will convert to the $[031]_{\alpha^{\prime \prime}}$ direction during SIM transformation (e.g. $[012]_{\beta} \rightarrow[031]_{\alpha^{\prime \prime}}$ ) based on their crystal orientation relationship [6], which is only $\sim 3$ degree from the (041) $)^{\prime \prime}$ plane normal (i.e. $\left[\begin{array}{lll}0 & 1.7 & 0.46\end{array}\right]_{\alpha "}$ using lattice parameters listed in Table 1 . Therefore, the strong $(041)_{\alpha \text { " }}$ fiber texture was directly transferred from the strong $\{210\}_{\beta}$ texture. The reason that the $\{210\}_{\beta}$ grains did not choose other $\alpha$ " directions is that the $[012]_{\beta} \rightarrow[031]_{\alpha}$ "transition gives the largest transformation strain (i.e. $4 \%$ using lattice parameter listed in Table 1), and most effectively accommodated the axial deformation stress. 
Figure 4 shows the evolution of the lattice strains of the $\{110\}_{\beta}$ and $\{310\}_{\beta}$ grain families in the loading direction with respect to the applied stress (Figures 4a and c) and the applied deformation strain (Figures $4 \mathrm{~b}$ and $\mathrm{d}$ ). Here, a grain family is defined as a group of grains that has their plane normal within 5 degree to the direction of interest. Lattice strain of each family was calculated relative to their initial status at zero stress, therefore does not include the effect of residual thermal stresses. It can be seen that, for both alloys, the $\{110\}_{\beta}$ family yielded first indicated by the first sharp turn on its strain curves at the lower stress and strain level. For $1 \mathrm{Fe}$, this happened at an applied stress and strain of $\sim 500 \mathrm{MPa}$ and $\sim 1.4 \%$ respectively (first dashed line in Figures $4 \mathrm{a}$ and b). For $2 \mathrm{Fe}$, this happened at applied stress and strain of $\sim 740 \mathrm{MPa}$ and $\sim 2 \%$ respectively (Figures $4 \mathrm{c}$ and $\mathrm{d}$ ). After that, the lattice strain of the $\{110\}_{\beta}$ family held constant, while the lattice strain of the $\{310\}_{\beta}$ family increased at a higher rate with increasing applied stress, carrying more load released from the $\{110\}_{\beta}$ family. For 1 Fe, the lattice strain of the $\{110\}_{\beta}$ family experienced a second turn at $620 \mathrm{MPa}$ and $\sim 2.2 \%$ stress and strain respectively (the second dashed line in Figures $4 \mathrm{a}$ and $\mathrm{b}$ ), and then increased as deformation continued until the stress reached $760 \mathrm{MPa}(2.7 \%$ strain), indicating that the load was picked up again by the $\{110\}_{\beta}$ family during this stage. This behavior, however, was not observed in $2 \mathrm{Fe}$. At a higher stress/strain level (e.g. $\sim 770 \mathrm{MPa}$ and $2.7 \%$ strain), the $\{310\}_{\beta}$ family in both alloys yielded. After that, the strain of the $\{110\}_{\beta}$ family remained unchanged, while the strain of the $\{310\}_{\beta}$ family increased at a slower rate as deformation continued.

It is believed that the yielding of the $\{110\}_{\beta}$ family in both alloys is caused by SIM transformation as it was accompanied by the emergence of SIM peaks on the diffraction image. For 1Fe, the SIM transformation appears to slow at a stress of $620 \mathrm{MPa}$, therefore the residual 
$\{110\}_{\beta}$ grains continued to stretch and bear more stress. At $770 \mathrm{MPa}$, SIM transformation was triggered again in the $\{110\}_{\beta}$ grains and caused the second yield as supported by its continuously decreased peak intensity (defined as the integrated area of a diffraction peak) and also unchanged peak width (Figures $5 \mathrm{a}$ and b). On the other hand, For the $\{310\}_{\beta}$ family, its peak intensity decreased, and peak width increased at stresses above $770 \mathrm{MPa}$ (Figures 5a and b), suggesting that the $\{310\}_{\beta}$ grains deformed by both SIM transformation and slip. Considering that the $\{310\}_{\beta}$ peak broadening started near $620 \mathrm{MPa}$ (Fig.5b), it is possible that the plastic deformation caused by slip may have occurred in the $\{310\}_{\beta}$ family at this stress level, which is earlier than its SIM transformation. For $2 \mathrm{Fe}$, the yielding of both grain families was accompanied by rapidly decreasing intensity and increasing peak width (Figs. 5c and d). It appears that the high $\beta$-phase stability associated with the extra Fe in $2 \mathrm{Fe}$ pushed the SIM onset stress high enough to trigger accompanying dislocation slip. Clearly, above discussions are based on the assumption that phase transformation only of part of a grain family will not change the internal stresses in the rest of that grain family if there is no internal residual stress before deformation. This assumption, although reasonable, is still debatable and requires more studies.

Figures 6 and 7 show the influence of the heat treating temperature and time on recoverable strain $\left(\varepsilon_{\mathrm{t}}\right)$, determined by subtracting the residual strain $\left(\varepsilon_{\mathrm{r}}\right)$ at zero stress from the total deformation strain as illustrated in Figure 6a. Generally, both alloys showed large recoverable strain (i.e. >3\%) after heat treatment at low temperatures for a short period, with the best result obtained at temperatures between 700 and $750^{\circ} \mathrm{C}$ for less than $10 \mathrm{~s}$. For example, a maximum of about $3.8 \%$ recoverable strain was obtained in $1 \mathrm{Fe}$ immediately after treatment at $750^{\circ} \mathrm{C}$ for $6 \mathrm{~s}$, and a maximum of about $3.5 \%$ recoverable strain was obtained in $2 \mathrm{Fe}$ after 
treatment at $700^{\circ} \mathrm{C}$ for $5 \mathrm{~s}$. The large recovery obtained on freshly produced samples, however, was not sustained after a relatively brief period of room temperature aging.

\subsection{Room temperature aging}

Figure 8 shows the effect of room temperature (RT) aging on samples heat treated at $700^{\circ} \mathrm{C}$ for 6 s. It can be seen that the SIM onset stress (calculated as the "yield strength", $\sigma_{0.2}$ ) of these samples increased within several hours after heat treatment, and it continued to increase at RT. In the meantime, the elongation and total strain recovery gradually decreased. After 4 days sitting at RT, the elongation of both samples dropped to below $4 \%$. Yield strength $\left(\sigma_{0.2}\right)$ of the $1 \mathrm{Fe}$ sample increased from about 530 to $730 \mathrm{MPa}$, while yield strength $\left(\sigma_{0.2}\right)$ of the $2 \mathrm{Fe}$ sample was raised from about 590 to $800 \mathrm{MPa}$.

Similar observations were made by Al-Zain et al. on Ti-Nb-Mo based alloys [22]. Based upon a TEM probe, they explained that the isothermal $\omega$-phase formed at RT thus decreasing the martensite phase transformation temperature and increasing the SIM onset stress. A similar mechanism is likely in Ti-Nb-Fe based alloys. Figures 9a and b show X-ray diffraction images of the 1 Fe sample after heat treating and after 30 hours of RT aging. Increased $\omega$-phase intensity by RT aging can be seen. From Figure 9c, the peak intensity of the $\{11 \overline{2} 2\}_{\omega}$ family slightly increased, while that of the $\{220\}_{\beta}$ family slightly decreased after 30 hours of RT aging, suggesting the $\beta$ - to $\omega$-phase transformation at RT. This is supported by the result of Rietveld refinement, which shows that the fraction of the $\omega$-phase in both alloys continuously increased during RT aging (Fig.10). After 2 days, the $\omega$-phase fraction increased from about $20.6 \pm 1$ mass $\%$ to $28.3 \pm 1.4$ mass $\%$ in the 1 Fe sample, and from $11 \pm 0.5$ mass $\%$ to $16.4 \pm 0.2$ mass $\%$ in 
the $2 \mathrm{Fe}$ sample. The lower $\omega$-phase fraction in $2 \mathrm{Fe}$ is due to the higher $\beta$-phase stability in this alloy caused by the higher Fe content.

According to Al-Zain et al. [22], lattice defects (e.g. dislocations) or non-equilibrium vacancies left in materials after low temperature short time annealing accelerates the diffusion process and promotes the formation of $\omega$-phase at RT; and increasing the annealing temperature suppresses RT aging. This is confirmed, at least in part, by Figure 11, which shows the effect of RT aging after heat treatment at $1000^{\circ} \mathrm{C}$ for 30 seconds. The aging influence on stress was much weaker compared to that shown in Figure 8. For example, after 15 days, the yield strength of $1 \mathrm{Fe}$ (Fig. 11a) was only increased from 440 to $480 \mathrm{MPa}$, while the elongation was almost unchanged, whereas the elongation of $2 \mathrm{Fe}$ (Fig. 11b) still dropped precipitously. The strain recovery of the fully annealed samples, however, is much smaller compared to those heat treated at lower temperatures for a short time.

For most of the $\beta$-Ti alloys, high mechanical properties and super-elastic response require significant microstructural refinement, further, much of this refinement occurs due to residual dislocation structures and textures from cold working after low temperature short time annealing [23]. The current work, along with previous data such as Al-Zain et al. in [22], show that this approach may not be practically applied in alloys that have low $\beta$-phase stability and/or high $\omega$ instability because of problematic continuous changes in constitutive behavior during room temperature storage and/or use.

\section{Conclusions}

The room temperature deformation behavior of Ti-17Nb-1Fe (1Fe) and Ti-15Nb-2Fe (2Fe) alloys was studied by synchrotron X-ray diffraction and tensile testing. It was found that: 
1. For both alloys, SIM phase transformation was responsible for the yield and the relatively large strain recovery at the macroscopic level. SIM occurred in the $\{110\}_{\beta}$ family ahead of others. While the deformation of the $\{110\}_{\beta}$ family in 1 Fe appeared to be simple SIM transformation, deformation of the $\{110\}_{\beta}$ family in $2 \mathrm{Fe}$ and that of the $\{310\}_{\beta}$ families at higher stress levels in both alloys was due to combined activity of phase transformation and dislocation slip.

2. Compared to $1 \mathrm{Fe}$, the higher $\beta$-phase stability in $2 \mathrm{Fe}$ caused by higher Fe content delayed the SIM transformation to a higher onset stress level. For the same reason, a strong $\{110\}_{\beta}$ texture was produced in $2 \mathrm{Fe}$ rather than the $\{210\}_{\beta}$ texture that was observed in $1 \mathrm{Fe}$ and has been observed in other metastable $\beta$-Ti alloys.

3. After a proper low temperature short time heat treatment, both alloys were capable of large strain recoveries of about $3.8 \%$ and $3.5 \%$ for $1 \mathrm{Fe}$ and $2 \mathrm{Fe}$, respectively, in freshly prepared samples.

4. Constitutive-behavior-altering, room temperature aging was observed in both alloys, at some level, in all conditions. During aging, $\omega$-phase was continuously formed, which increased the yield strength (also SIM onset stress), and decreased the ductility and strain recovery. Scientists and engineers should give heed to this phenomenon in material design, selection and applications, particularly in thin and highly refined engineering sections such as sheet, wire, and tubing.

\section{Acknowledgement}


This study was funded by Fort Wayne Metals Research Products Corp. Use of the synchrotron X-ray at APS was granted by the U.S. Department of Energy, Office of Science, under Contract No. DEAC02-06CH11357. Data were analyzed by using FIT2D, Maud and GSAS software.

\section{References}

1. A.R. Pelton, V. Schroeder, M.R. Mitchell, Xiao-Yan Gong, M. Barney, S.W. Robertson, J Mech Behav Biomed Mater, 1 (2008) 153-164

2. T.W. Duerig and M. Wholey, Min Invas Ther \& Allied Technol, 11 (2002), 173-178

3. Z. Jia, J. Tu, K. Wang, G. Jiang, W. Wang, J Vasc Interv Radiol 26 (2015) 1375-1377

4. P. Jetty, S.Jayaram, J. Veinot, and M. Pratt, J Vasc Surg 58 (2013) 1388-1390

5. E. McLucas, Y. Rochev, W. M. Carroll, T. J. Smith, J Mater Sci: Mater Med (2008) 19:975-980

6. H.Y. Kim, Y. Ikehara, J.I. Kim, H. Hosoda, S. Miyazaki, Acta Mater. 54 (2006) 24192429

7. Y.L. Hao, S.J. Li, S.Y. Sun, C.Y. Zheng, R. Yang, Acta Biomater 3 (2007) 277-286

8. S. Miyazaki, H.Y. Kim and H. Hosoda, Mater. Sci,. Eng., 438-440 (2006) 18-24

9. M.H. Wu, P.A. Russo and J.G. Ferrero, SMST-2003, eds. A.R. Pelton and T. Duerig, SMST society, Menlo Park, California, 2003, pp.81-90

10. S. Cai, J.E. Schaffer, Y. Ren, APL 106 (2015) 131907

11. T. Zhou, M. Aindow, S.P. Alpay, M.J. Blackburn, M.H. Wu, Scripta Mater. 50 (2004) $343-348$

12. P.J.S. Buenconsejo, H.Y. Kim, S. Miyazaki, Acta Mater 57 (2009) 2509-2515

13. S. Cai, M.R. Daymond, Y. Ren, J.E. Schaffer, Acta Mater., 61( 2013) 6830-6842 
14. S. Hao, L. Cui , Z. Chen, D. Jiang, Y. Shao, J. Jiang, M. Du, Y. Wang, D. E. Brown, and Y. Ren, Adv. Mater. 25 (2013) 1199-1202

15. A.P. Hammersley, FIT2D V9.129 reference manual V3.1, ESRF internal report, 1998

16. H.M. Rietveld, J Appl Crystallogr 2 (1969) 65-71.

17. L. Lutterotti, S. Matthies, H.-R. Wenk, A.S. Schulz and J.W.Jr. Richardson, J. Appl. Phys. 81 (1997) 594

18. A.C. Larson, R.B. Von Dreele, Report No. LAUR 86-748, Los Alamos National Laboratory, 2004.

19. C. Baker, Metal Sci. J., 5 (1971) 92-100

20. T.W. Duerig, J. Albrecht, D. Richter and P. Fischer, Acta Metall., 30 (1982) 2161-2172

21. S. Cai, J.E. Schaffer, Y. Ren and M.R. Daymond, Acta Mater. 87 (2015) 390-398

22. Y. Al-Zain, Y. Sato, H.Y. Kim, H. Hosoda, T.H. Nam, S. Miyazaki, Acta Mater. 60 (2012) 2437-2447

23. H.Y. Kim, T. Sasaki, K. Okutsu, J.I. Kim, T. Inamura, H. Hosoda and S. Miyazaki, Acta Mater. 54 (2006) 423-433

Figure 1 Stress strain curves of $1 \mathrm{Fe}, \mathrm{a})$, and $2 \mathrm{Fe}$, d), of the in-situ tensile test; diffraction images of $1 \mathrm{Fe}, \mathrm{b}$ ), and $2 \mathrm{Fe}, \mathrm{e}$ ), before deformation; diffraction images of $1 \mathrm{Fe}, \mathrm{c})$, and $2 \mathrm{Fe}, \mathrm{f}$ ), at the strain of 3\%. Dots in a) and d) show the frequency of X-ray data collection. The specimen axial direction in b), c), e) and f) is vertical from the beam center. 
Figure 2 Inverse pole figures of sample's axial direction in different phases in 1Fe during deformation.

Figure 3 Inverse pole figures of sample's axial direction in different phases in $2 \mathrm{Fe}$ during deformation.

Figure 4 Lattice strain evolution of $\{110\}_{\beta}$ and $\{310\}_{\beta}$ families in $1 \mathrm{Fe}$ (a and b) and $2 \mathrm{Fe}$ (c and d) during deformation. Errors of lattice strain are less than $0.25 \times 10^{-3}$.

Figure 5 Evolution of peak intensity (a and c) and peak broadening (b and d) of $\{110\}_{\beta}$ and $\{310\}_{\beta}$ families in $1 \mathrm{Fe}(\mathrm{a}$ and $\mathrm{b}$ ) and $2 \mathrm{Fe}(\mathrm{c}$ and $\mathrm{d}$ ). Both the peak width and intensity are normalized to the start points and shifted for clarity.

Figure 6 Stress-strain curves of 1Fe a) heat treated at different temperature for 6 seconds, and b) heat treated at $750^{\circ} \mathrm{C}$ for different amount of time.

Figure 7 Stress-strain curves of $2 \mathrm{Fe}$ a) heat treated at different temperature for 10 seconds, and b) heat treated at $750^{\circ} \mathrm{C}$ for different amount of time.

Figure 8 Effect of room temperature aging on a) $1 \mathrm{Fe}$ and b) $2 \mathrm{Fe}$ after heat treated at $700^{\circ} \mathrm{C}$ for 6 seconds. Sample diameter is $\sim 0.4 \mathrm{~mm}$.

Figure 9 Diffraction image of the 1Fe sample a) after heat treating, b) after 30 hour aging, and c) change of peak intensities of the $\{11 \overline{2} 2\}_{\omega}$ and the $\{220\}_{\beta}$ families during aging. Peak intensity in c) was integrated along the $360^{\circ}$ azimuthal angle.

Figure 10 Evolution of $\omega$-phase fraction in samples heat treated at $700^{\circ} \mathrm{C}$ for 6 seconds during room temperature aging. 
Figure 11 Effect of room temperature aging on a) $1 \mathrm{Fe}$ and b) $2 \mathrm{Fe}$ after heat treated at $1000^{\circ} \mathrm{C}$ for 30 seconds. Sample diameter is $\sim 0.4 \mathrm{~mm}$. 

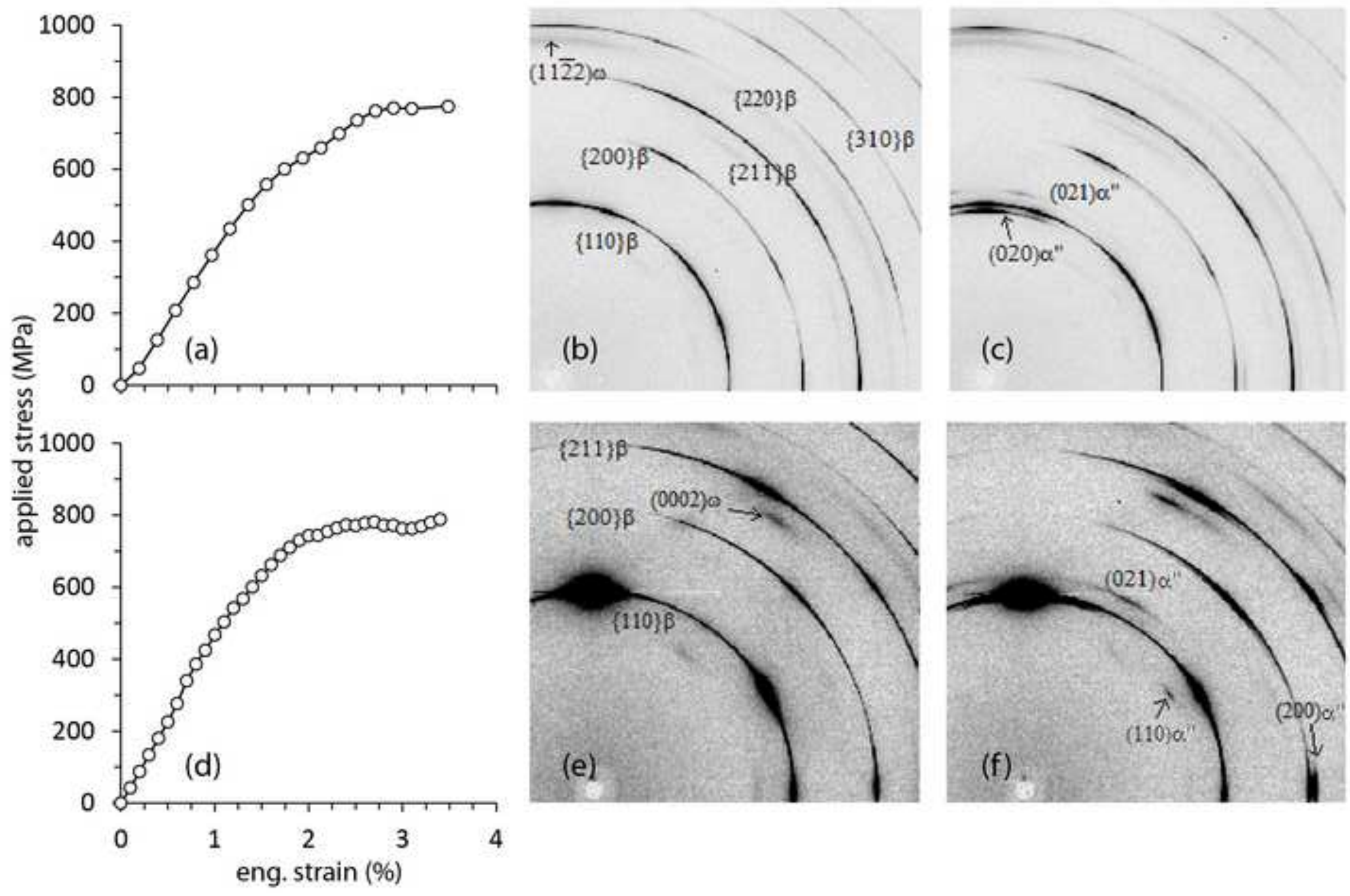


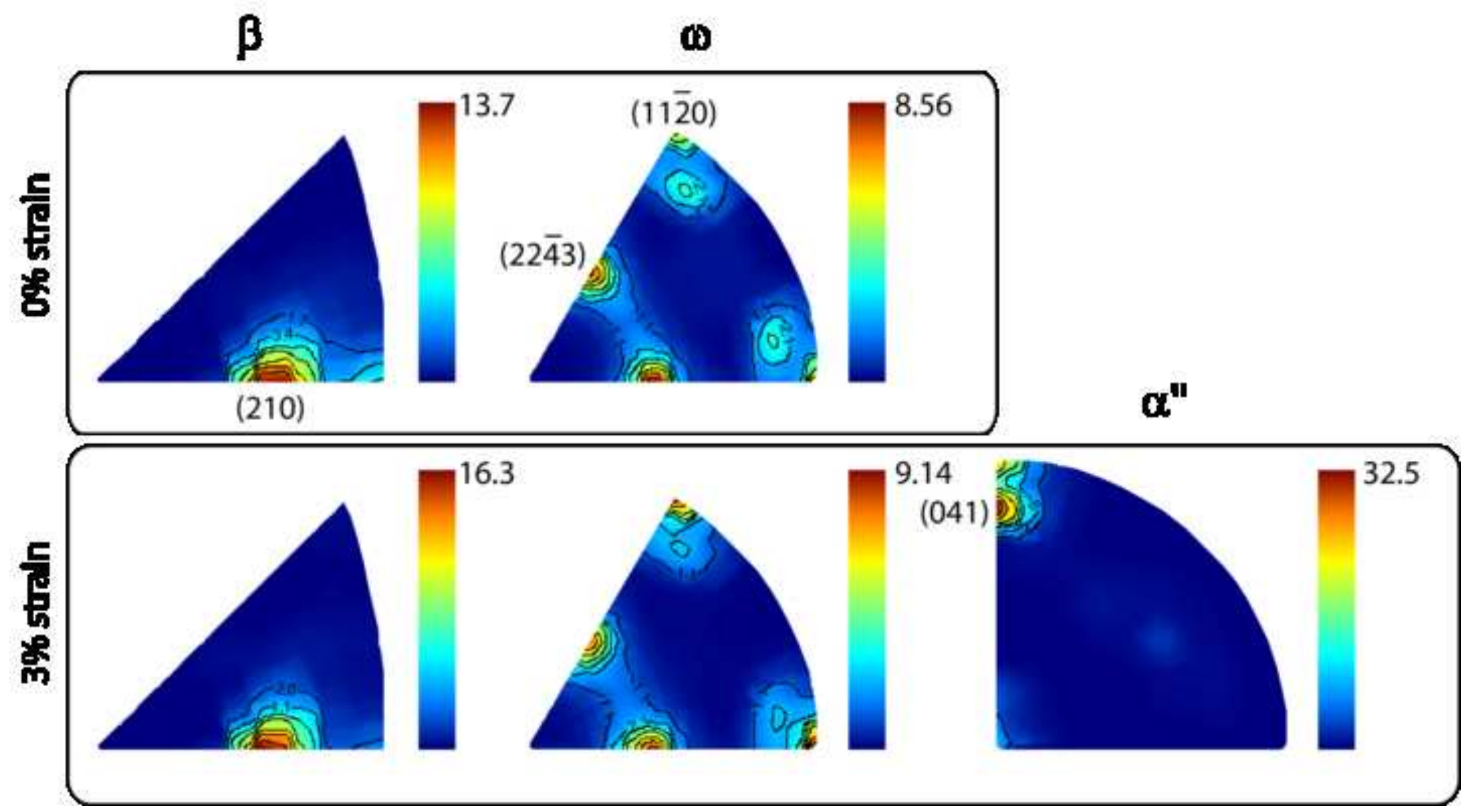




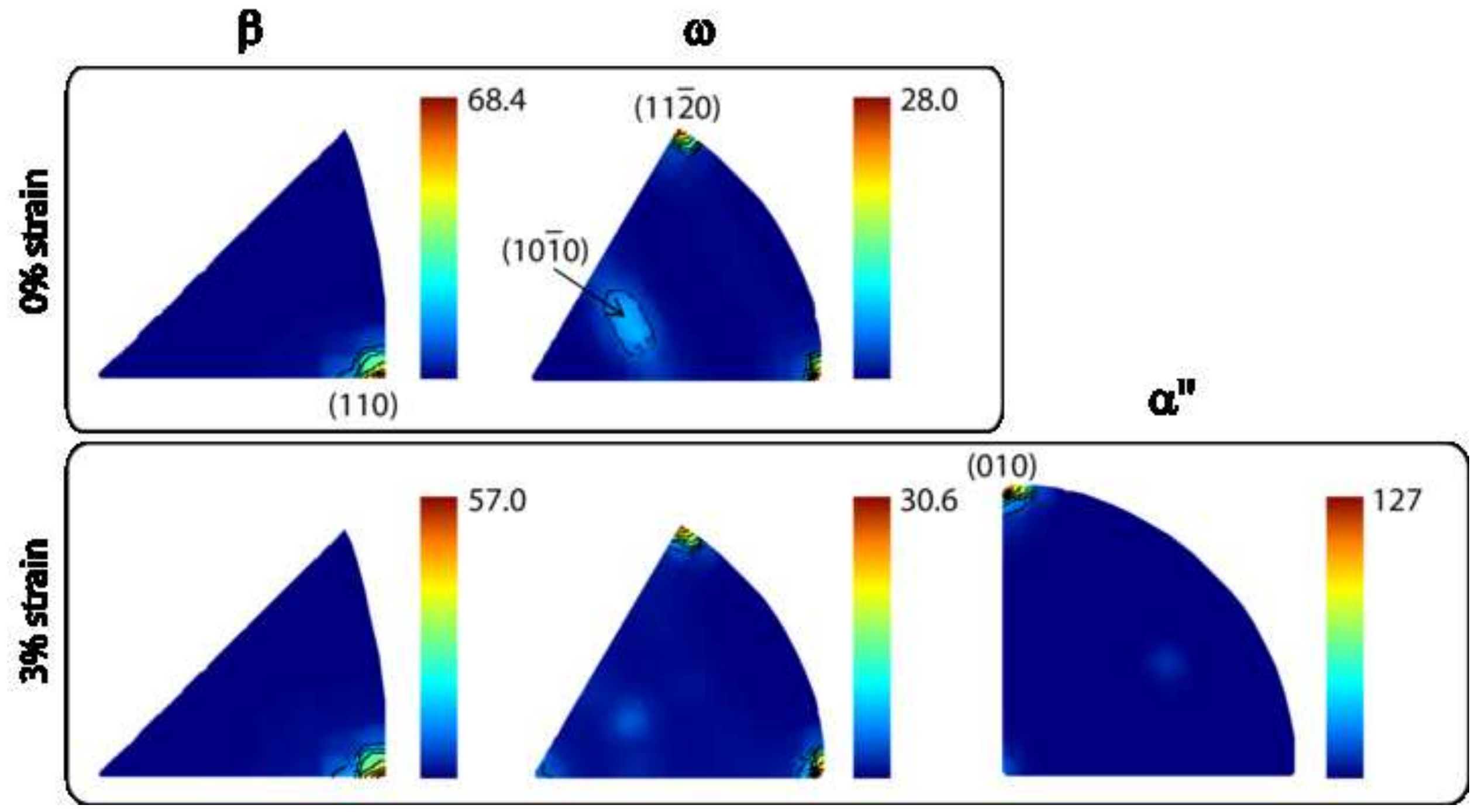



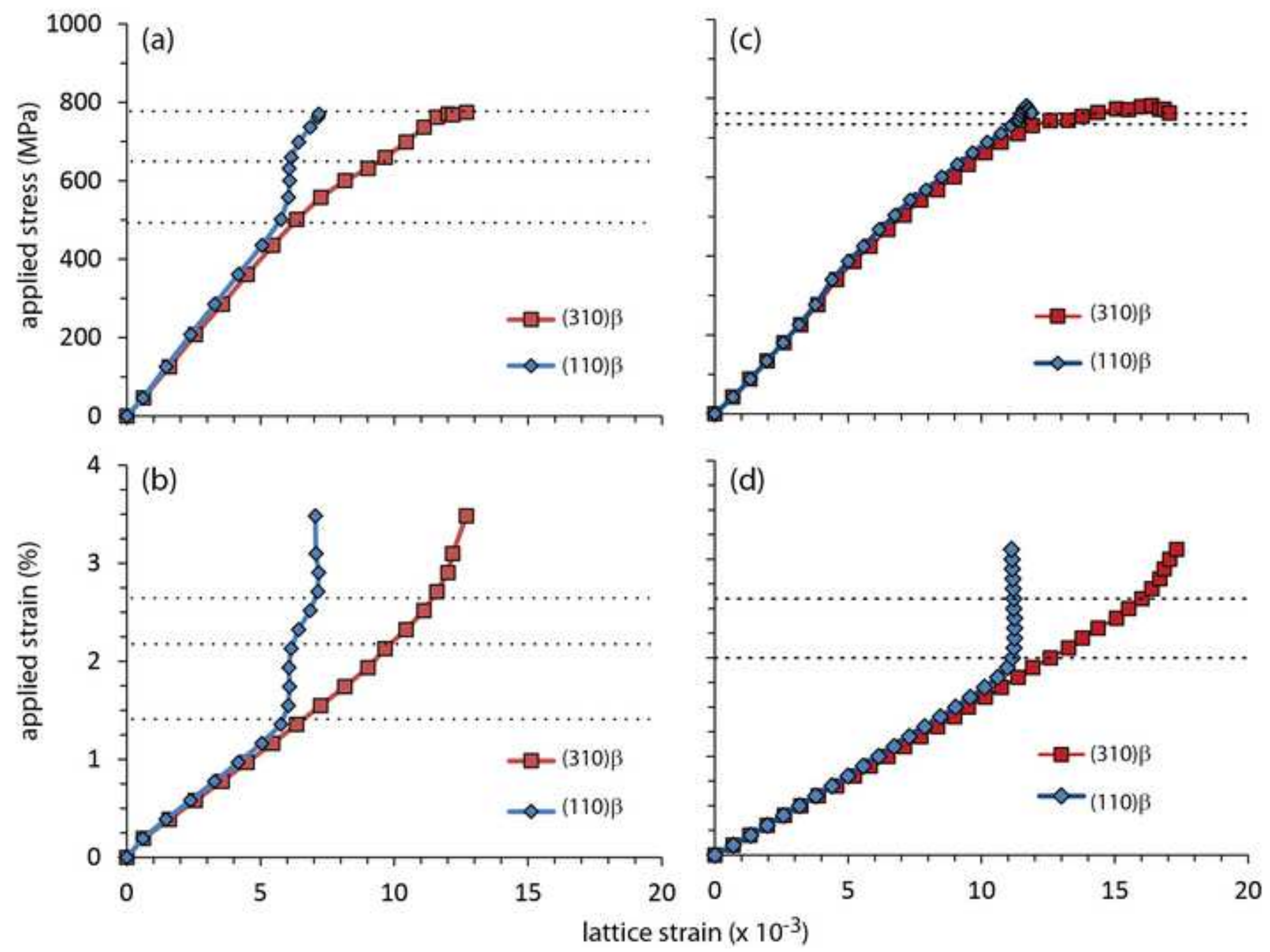

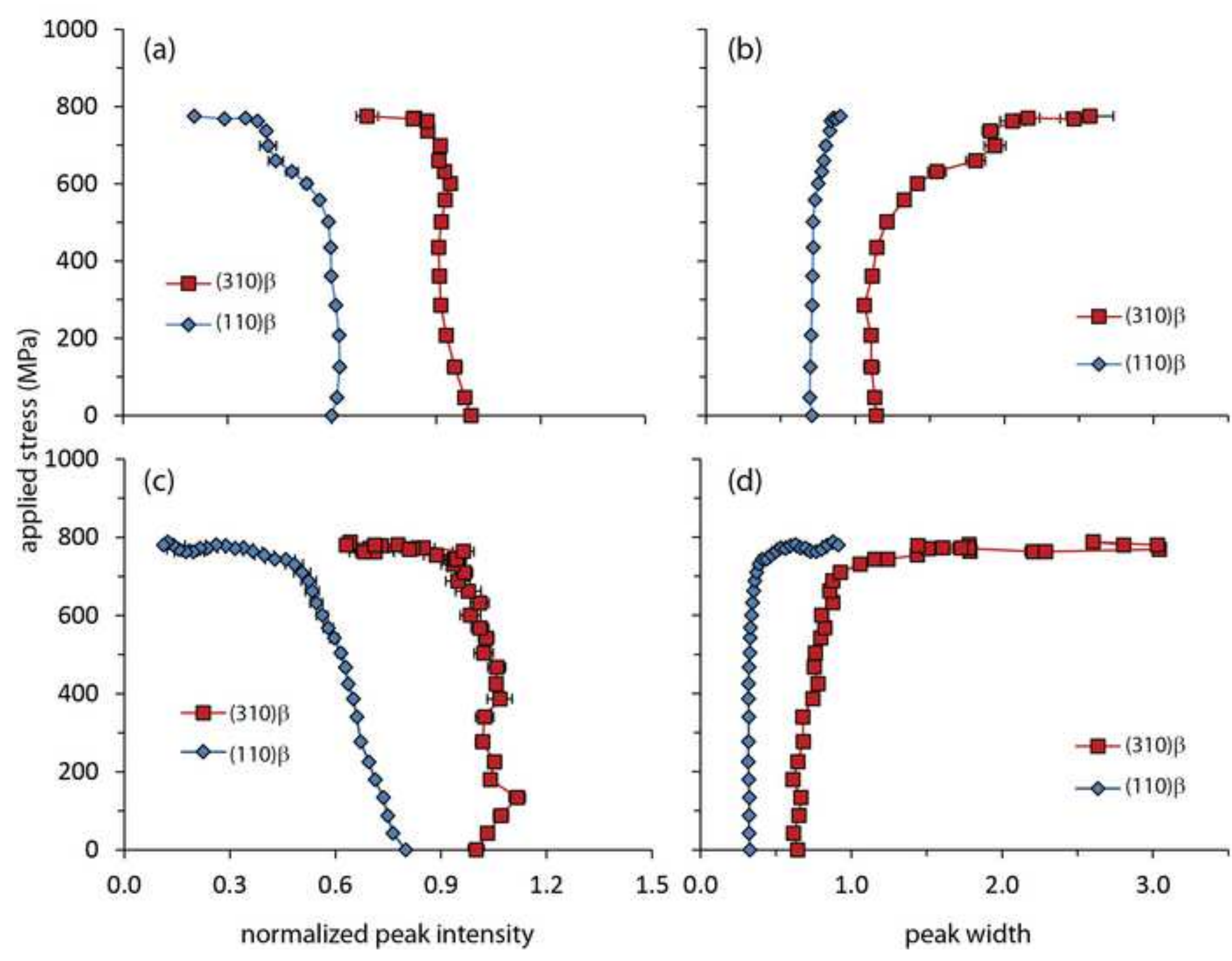

(d)

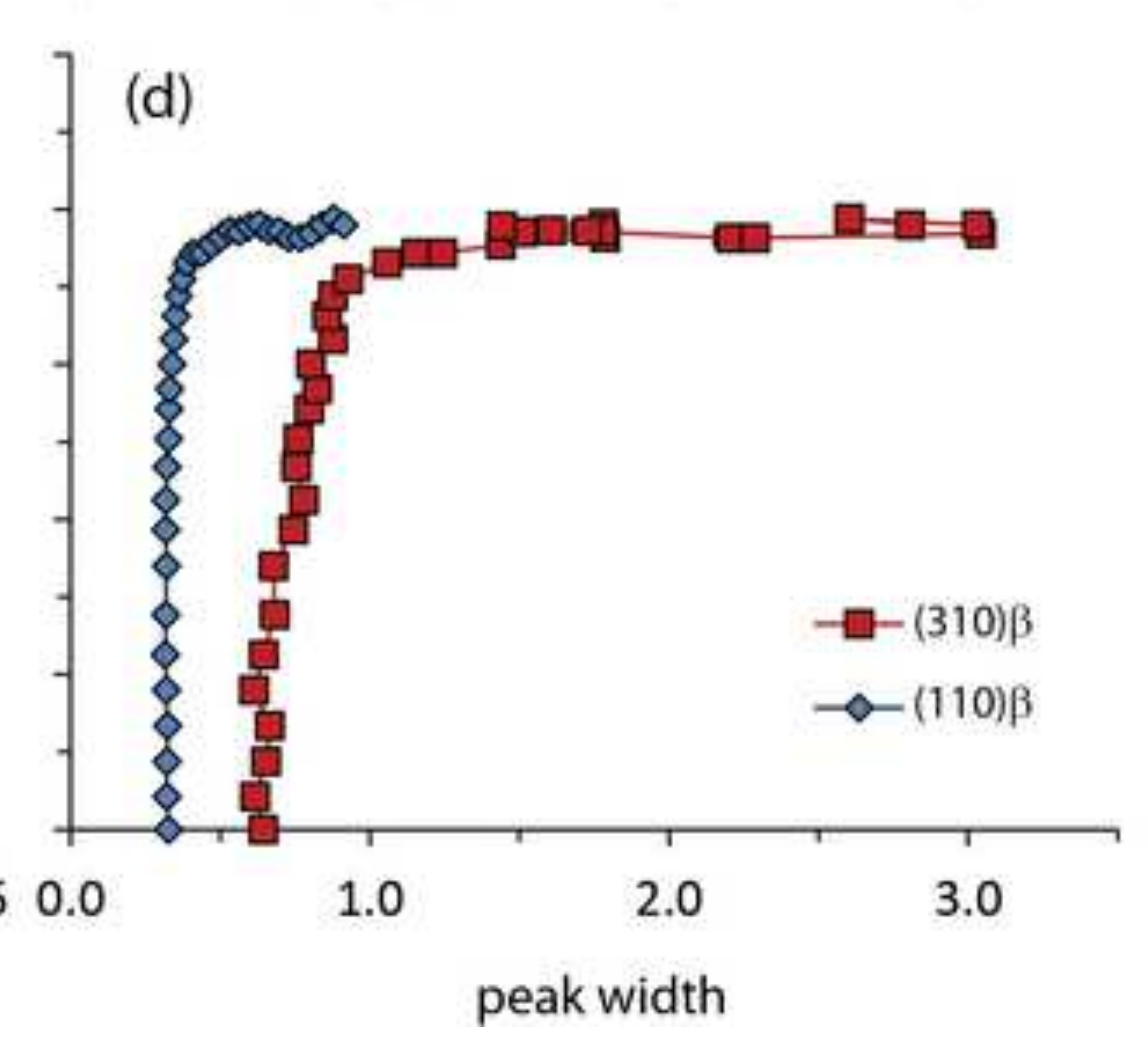




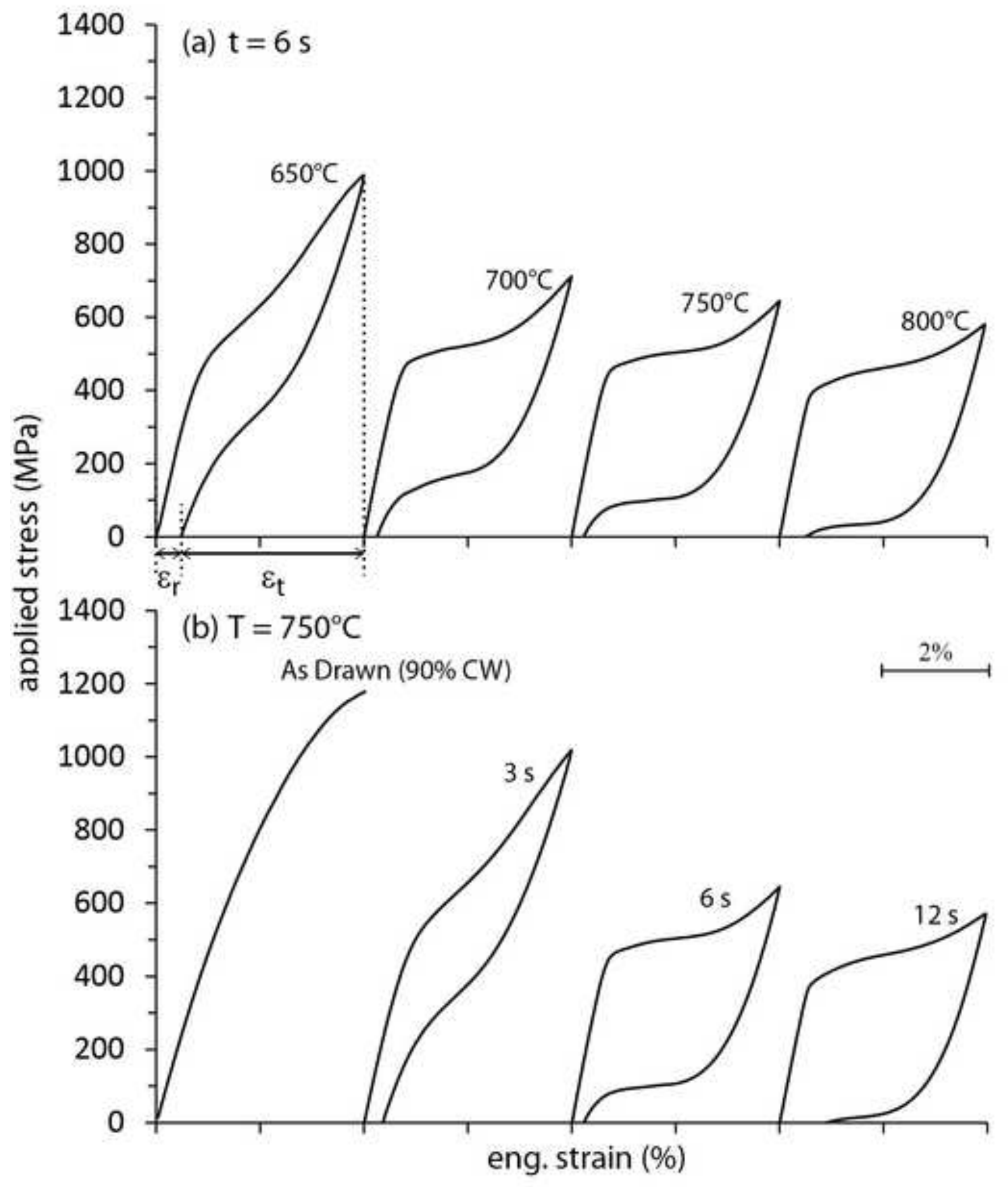




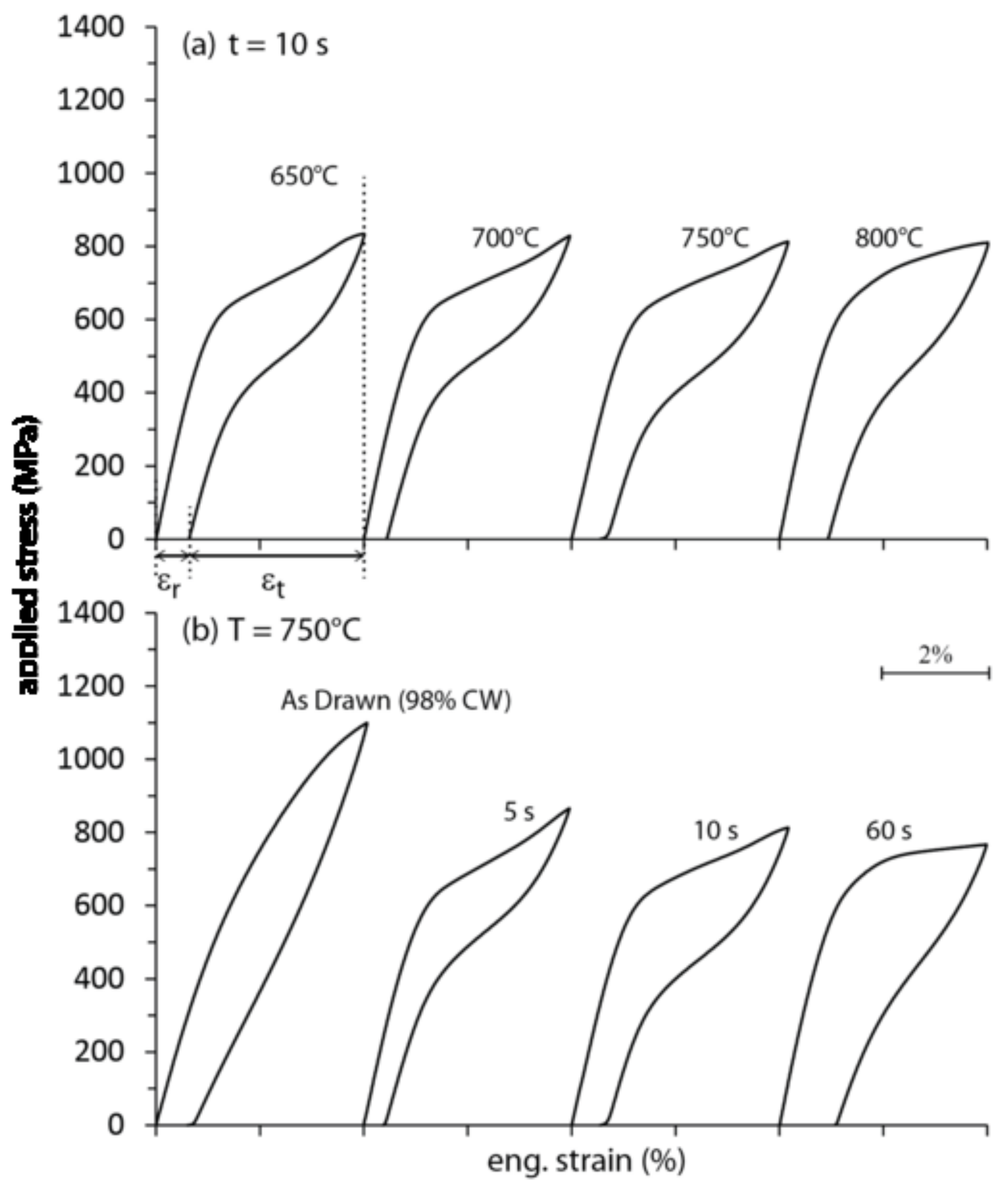




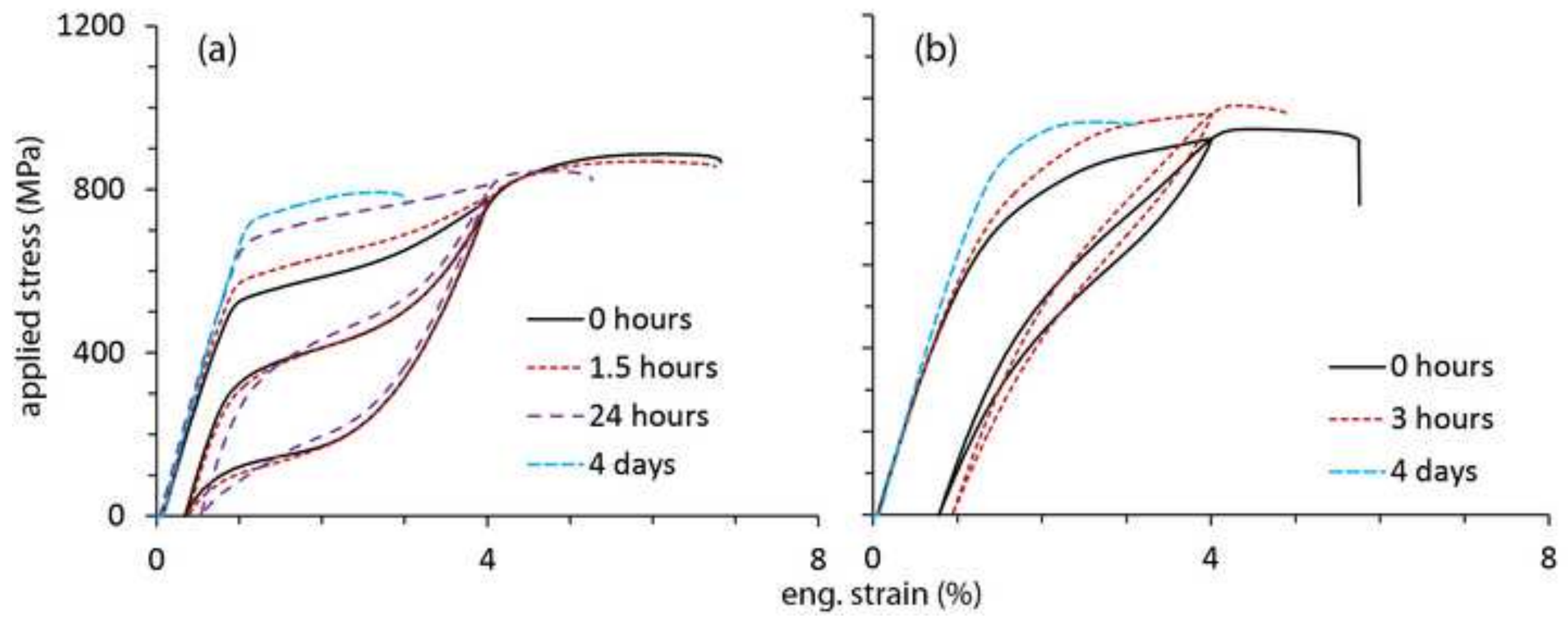



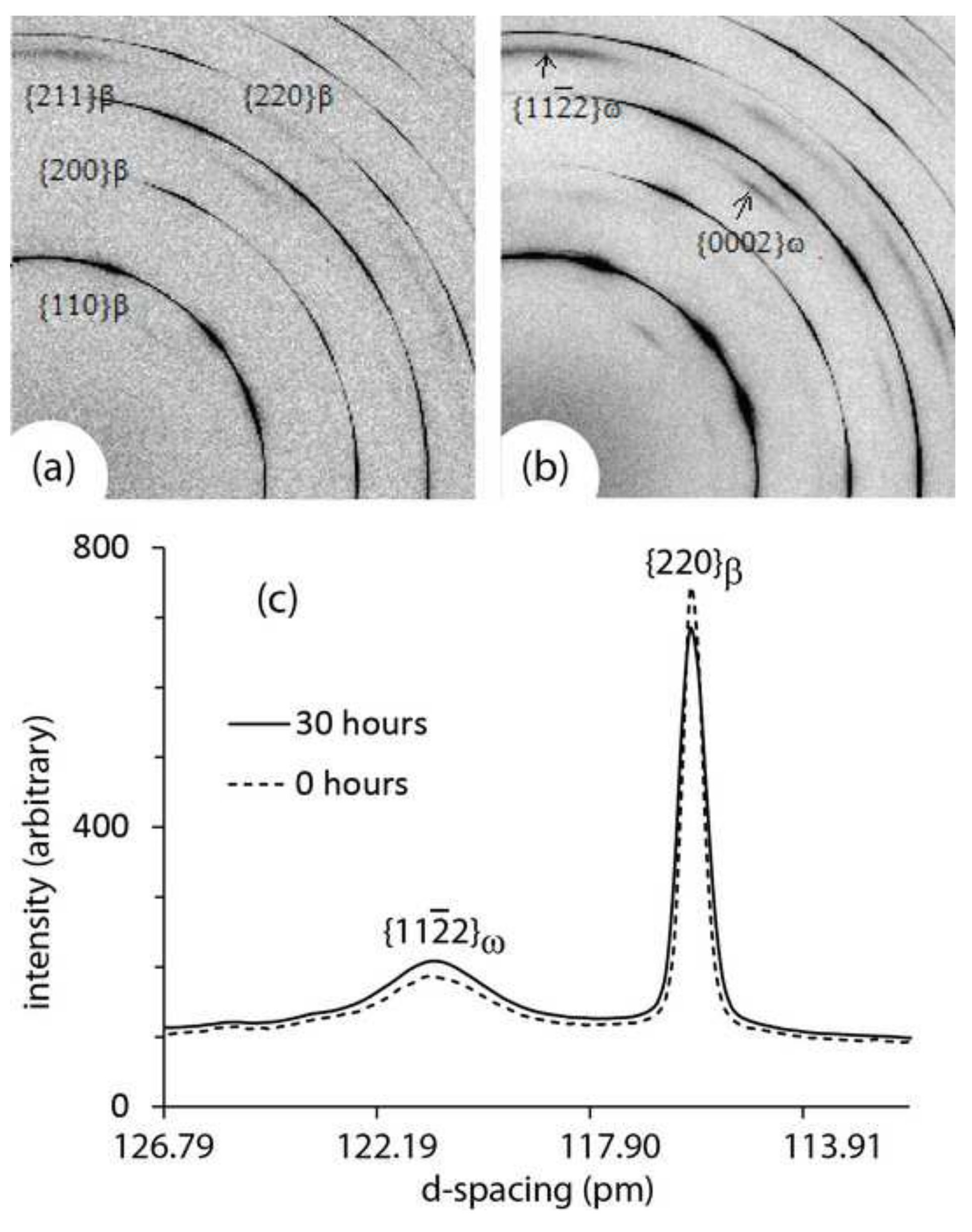

Figure(s)

)

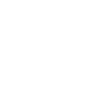




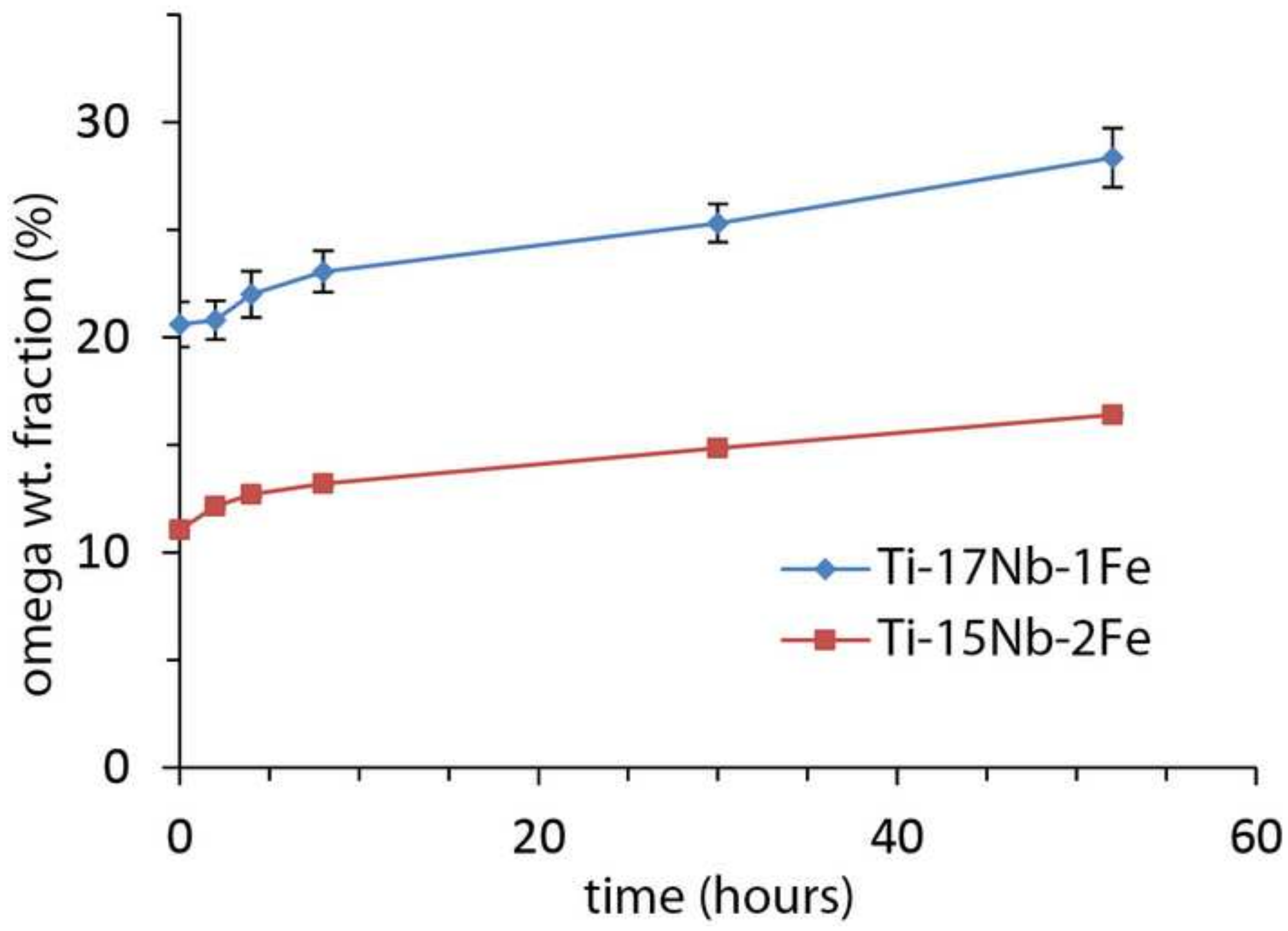




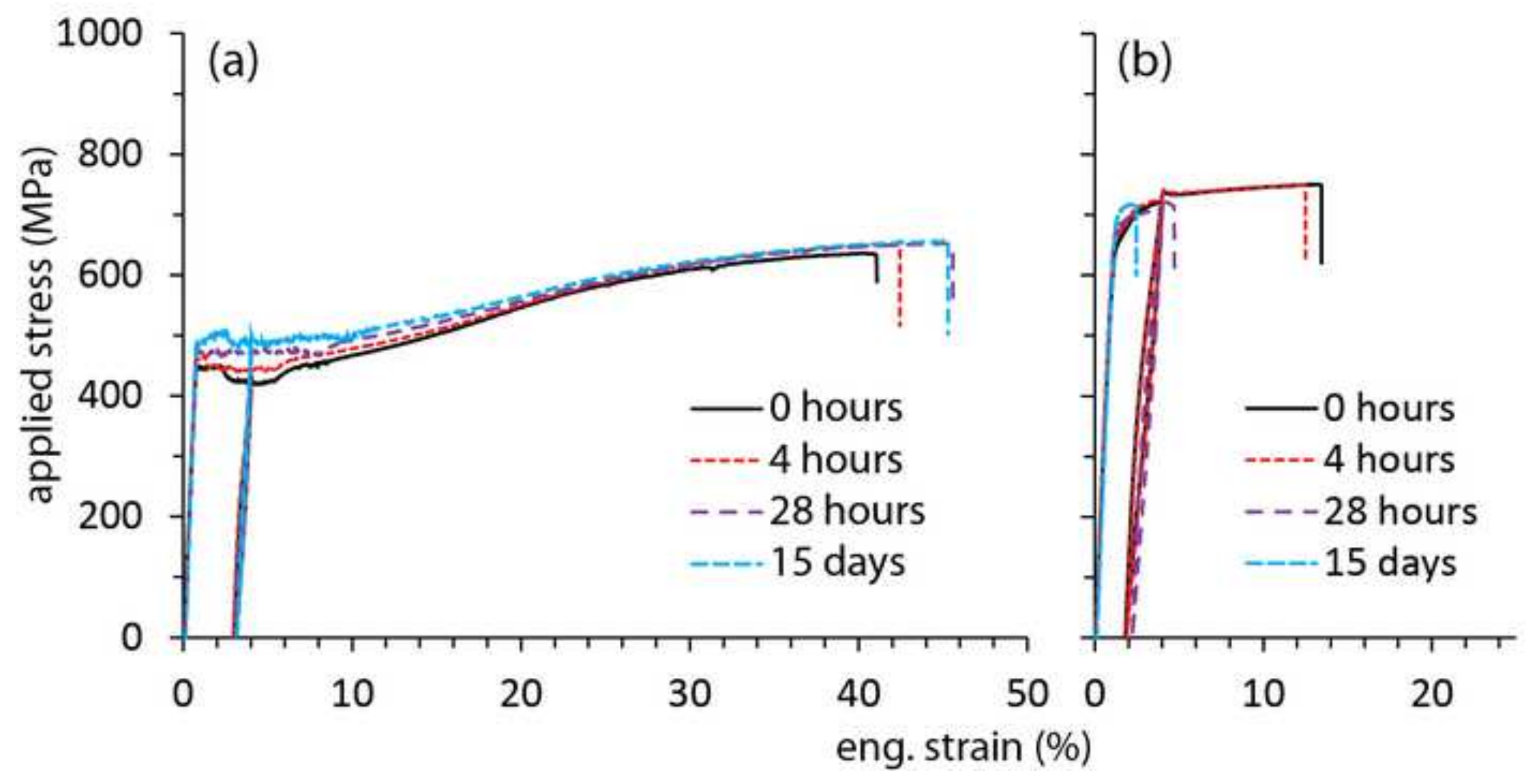




\begin{tabular}{ccccc}
\hline alloy & phase & $\mathrm{a}(\mathrm{pm})$ & $\mathrm{b}(\mathrm{pm})$ & $\mathrm{c}(\mathrm{pm})$ \\
\hline \multirow{2}{*}{ 1Fe } & $\beta$ & 327.65 & & \\
& $\omega$ & 463.26 & & 283.37 \\
& $\alpha^{\prime \prime}$ & 318.97 & 483.58 & 464.51 \\
\hline \multirow{3}{*}{$2 \mathrm{Fe}$} & $\beta$ & 327.94 & & \\
& $\omega$ & 463.59 & & 283.65 \\
& $\alpha^{\prime \prime}$ & 319.64 & 476.02 & 466.18 \\
\hline
\end{tabular}

Table 1 Lattice parameters of different phases in each alloy. Lattice parameter of the $\alpha$ "-phase is obtained at a strain of $3 \%$. 